\title{
Baicalein Is a Phytohormone that Signals Through the Progesterone and Glucocorticoid Receptors
}

\author{
Julia R. Austin ${ }^{1}$ (D) Brenna J. Kirkpatrick ${ }^{1} \cdot$ Rocío Rivera Rodríguez $^{2} \cdot$ Michael E. Johnson $^{1} \cdot$ Daniel D. Lantvit ${ }^{1}$. \\ Joanna E. Burdette ${ }^{1}$ (B)
}

Received: 5 December 2019 / Accepted: 13 February 2020 / Published online: 7 March 2020

(C) Springer Science+Business Media, LLC, part of Springer Nature 2020

\begin{abstract}
While flavonoids have been studied extensively for estrogen receptor activity, they have not been well studied for their ability to modify progesterone receptor (PR) and glucocorticoid receptor (GR) signaling. Three flavonoid compounds, tangeretin, wogonin, and baicalein, were selected for testing for PR and GR activity based on their structural similarity to known phytoprogesterone-like compounds. Each compound was docked in the binding pocket of PR and GR. Of these compounds, baicalein was predicted to be most likely to bind to both receptors. A fluorescence polarization competitive binding assay for PR and GR confirmed that baicalein binds to both the PR and GR with $\mathrm{IC}_{50}$ values of $15.30 \mu \mathrm{M}$ and $19.26 \mu \mathrm{M}$, respectively. In Ishikawa PR-B and T47D cells, baicalein acted as a PR antagonist in a hormone response element (HRE) luciferase (Luc) assay. In OVCAR5 cells, which only express GR, baicalein was a GR agonist via an HRE/Luc assay and induced GR target genes, FKBP5 and GILZ. RU486, a PR and GR antagonist, abrogated baicalein's activity in OVCAR5 cells, confirming baicalein's activity is mediated through the GR. In vivo, baicalein administered intraperitoneally to female mice twice a week for 4 weeks at a dose of $25 \mathrm{mg} / \mathrm{kg}$ induced the GR target gene GILZ in the reproductive tract, which was blocked by RU486. In summary, baicalein has PR antagonist and GR agonist activity in vitro and demonstrates GR agonist activity in the uterus in vivo.
\end{abstract}

Keywords Phytoprogestin $\cdot$ Phytocorticoid $\cdot$ Botanical supplement $\cdot$ Natural product $\cdot$ Scutellaria baicalensis

\section{Introduction}

Progesterone is a steroid hormone that plays a role in the regulation of hormone-dependent cancers [1]. Progesterone affects many of the reproductive tissues, including the breast, endometrium, and ovary. In the uterus, progesterone counteracts the proliferative effect of estrogen on the endometrial epithelium [1]. Due to this function, progesterone is used clinically for the treatment of endometrial cancer and is also

Electronic supplementary material The online version of this article (https://doi.org/10.1007/s12672-020-00382-6) contains supplementary material, which is available to authorized users.

Joanna E. Burdette

joannab@uic.edu

1 Department of Pharmaceutical Sciences, Center for Biomolecular Sciences, College of Pharmacy, University of Illinois at Chicago, Chicago, IL 60607, USA

2 Department of Chemistry, College of Natural Sciences, University of Puerto Rico, Río Piedras Campus, San Juan 00925, Puerto Rico shown to protect against the development of endometrial cancer in women on high-dose progestins [2,3]. Progesterone is not orally bioavailable, so synthetic forms of progesterone, termed progestins, are prescribed to women for uterine fibroids, endometriosis, and endometrial cancer [4, 5]. Women who consume oral contraceptives that contain progestins or have multiple pregnancies due to high progesterone levels have an overall decreased risk of ovarian cancer [6, 7]. Progesterone binds to the progesterone receptor (PR), which is a part of the nuclear receptor family and has structural similarity to the androgen, glucocorticoid, and mineralocorticoid receptors [8]. Ligands for the PR can have promiscuous binding for the androgen receptor (AR) and the glucocorticoid receptor (GR), which leads to side effects of cardiovascular disease, stroke, water retention, and weight gain $[9,10]$. There is a need to identify orally available progesterone-like compounds with reduced side effect profiles that could potentially be used in the treatment and prevention of gynecological diseases.

Botanical dietary supplements are becoming increasingly popular. In 2018, $\$ 8.8$ billion was spent on botanical dietary 
supplement sales [11]. Women are turning to botanical supplements to alleviate their menopausal symptoms, PMS, dysmenorrhea, infertility, and other gynecological ailments [12, 13]. Steroid receptor ligands have been identified in herbal supplements with the most well characterized of these categorized as phytoestrogens [12]. Phytoestrogens are plant compounds that can be structurally similar and/or act functionally similar to estrogens usually by binding to the estrogen receptor and triggering its transcriptional activation [14]. Botanical dietary supplements that contain phytoestrogenic compounds have been proposed for use in the treatment of various gynecological ailments, including PMS and menopausal symptoms in the USA [12].

Botanical dietary supplements are usually a mixture of compounds, and there is increasing evidence that botanical dietary supplements contain phytosteroidal compounds other than phytoestrogens [15]. Recent studies have shown that there are compounds in botanical dietary supplements that mitigate uterine proliferative effects of phytoestrogens [16, 17]. These compounds that counteract the effect of phytoestrogens have been determined in part to be phytoprogestins, plant compounds that can bind to the progesterone receptor and trigger transcriptional action. The progestogenic activity of two such compounds, apigenin and kaempferol, has been characterized in vitro and in vivo [16, 17]. Both apigenin and kaempferol are flavonoids that are found in a variety of botanicals, fruits, and vegetables [16, 18]. Most notably, apigenin and kaempferol were able to block proliferation induced by genistein, a phytoestrogen, in ovariectomized rats, indicating that they are behaving similarly to progesterone. Supplements that contain both phytoestrogens and phytoprogestins would be safer in the uterus as they are less likely to stimulate endometrial epithelial proliferation $[16,17]$.

In addition to the progestogenic activity of botanicals, interaction of botanical compounds with GR is also of interest, since many synthetic ligands bind both receptors. GR is a ubiquitous receptor that acts like a transcription factor once bound to ligand [19]. One of the main functions of GR is immunosuppression and reducing inflammation [19], and many botanical supplements are used to reduce inflammation or have traditional use for inflammatory conditions [20-22]. Botanicals used to reduce inflammation have not been extensively studied for their ability to interact with and activate GR $[23,24]$. Understanding the glucocorticoid activity of botanicals could help us understand their anti-inflammatory mechanism and explain their traditional use.

To identify compounds that have activity by signaling through PR, a literature search was performed for compounds that were similar in structure to characterized phytoprogestins, apigenin, and kaempferol [16, 17]. Three flavonoid compounds were selected: tangeretin, wogonin, and baicalein. These three compounds were also tested for their phytocorticoid activity, as many ligands can bind to both receptors. Of the compounds tested, baicalein was found to be a PR antagonist and a GR agonist and induce GR signaling in vitro and in vivo.

\section{Material and Methods}

\section{Cell Culture and Small Molecules}

Ishikawa cells stably expressing PR-B under the control of CMV [25] were graciously donated by Dr. Leen J. Blok, Department of Obstetrics and Gynecology, Erasmus, Medical Center, Rotterdam, The Netherlands. Ishikawa PR-B cells were maintained in phenol red free DMEM/F12 media (11039-021, Invitrogen) and supplemented with $5 \%$ charcoal dextran stripped FBS, and selection antibiotics $(500 \mu \mathrm{g} / \mathrm{mL}$ G418 and $250 \mu \mathrm{g} / \mathrm{mL}$ hygromycin). Expression of PR was validated by western blot (Supplementary Fig. 1A). T47D cells were purchased from ATCC and maintained in RPMI 1640 (MT10040CV, Corning) supplemented with $10 \%$ FBS, $2.25 \mathrm{~g} / 500 \mathrm{~mL}$ of glucose, $2 \mathrm{mM}$ L-glutamine (25030081, Thermo Scientific, Waltham MA), $1 \%$ sodium pyruvate (11360070, Thermo Scientific, Waltham, MA), $0.75 \mathrm{~g} /$ $500 \mathrm{~mL}$ of sodium bicarbonate, $1.19 \mathrm{~g} / 500 \mathrm{~mL}$ of HEPES, 0.2 units $/ \mathrm{mL}$ of insulin (700112P, Gemini Bioproducts, West Sacramento, CA), and $1 \%$ penicillin/streptomycin. OVCAR5 cells were maintained in MEM media (11095098, Thermo Scientific, Waltham, MA) supplemented with $10 \%$ FBS, $2 \mathrm{mM} \mathrm{L-glutamine,} 1 \%$ nonessential amino acids (11140050, Thermo Scientific, Waltham, MA), $1 \%$ sodium pyruvate (11360070, Thermo Scientific, Waltham, MA), and $1 \%$ penicillin/ streptomycin. MDA-MB-231 cells were purchased from ATCC and maintained in DMEM media (1155065, Thermo Scientific, Waltham, MA) supplemented with $5 \%$ FBS and $1 \%$ penicillin/streptomycin. T47D, OVCAR5, and MDA-MB-231 cells were plated in steroid-free media, which lacked phenol red and contained double charcoal-stripped FBS, 24 or $48 \mathrm{~h}$ before beginning any experiment. All cells were maintained in a humified incubator at $37{ }^{\circ} \mathrm{C}$ and $5 \% \mathrm{CO}_{2}$. All cells were validated by STR analysis.

Progesterone (P0130-25G, Sigma Aldrich, St. Louis, MO), RU486 (10006317, Cayman Chemical, Ann Arbor, MI), baicalein (70610, Cayman Chemical, Ann Arbor, MI), 17 $\beta$ estradiol (10006315, Cayman Chemical, Ann Arbor, MI), tangeretin (10009911, Cayman Chemical, Ann Arbor, MI), wogonin (14248, Cayman Chemical, Ann Arbor, MI), and dexamethasone (11015, Cayman Chemical, Ann Arbor, MI) were dissolved in DMSO at $\times 1000$ final concentration to ensure $0.1 \%$ DMSO in media. 


\section{HRE Luc Assay}

Transcriptional activity was measured using a plasmid expressing the thymidine kinase promoter with two steroid response elements (ACAAGA half site) that bind PR and GR [26] as previously described [18]. To measure hormone response element/luciferase (HRE/Luc), Ishikawa PR-B (40,000 per well), T47D (50,000 per well), OVCAR5 (15,000 per well), or MDA-MB-231 cells $(40,000$ per well) were plated in 24-well plates. After $24 \mathrm{~h}$, the luciferase construct and a $\beta$-galactosidase construct under the control of a CMV promoter was transfected into Ishikawa PR-B, OVCAR5, MDA-MB-231 (200 ng/well of HRE/Luc and $100 \mathrm{ng} /$ well of $\beta$-galactosidase), or T47D cells (100 ng/well of HRE/Luc and $100 \mathrm{ng} /$ well of $\beta$-galactosidase). Transfections were carried out with LT1 transfection reagent per the manufacturer's instructions (MIR 2304, Mirus Bio, Madison, WI). Following $24 \mathrm{~h}$ treatments with pure compounds, $110 \mu \mathrm{L}$ lysis buffer was added to each well and cells were frozen at $-80^{\circ} \mathrm{C}$. Luciferase activity in relative luminance units (RLU) was measured on a synergy BioTek plate reader. The first six determinations of RLU were averaged for each well. Luciferase activity was normalized to $\beta$ galactosidase and then normalized to vehicle control for each experiment [16].

\section{Molecular Modeling of Baicalein, Tangeretin, Wogonin with the Progesterone Receptor, and Glucocorticoid Receptor}

For the docking analyses with PR, chain A of the crystal structure 1A28 was used as the receptor, which was prepared by MGLTools [27] to add polar hydrogen and charges. The $3 \mathrm{D}$ structures of baicalein, tangeretin, and wogonin were similarly prepared for docking by MGLTools [27]. A rectangular box $\left(18 \times 16 \times 18 \AA^{3}\right)$ centered around the $\mathrm{C} 8$ carbon of the progesterone ligand in $1 \mathrm{~A} 28$ defined the region that the ligands could explore within the static receptor structure, which included essentially all of the progesterone binding site. Initial docking indicated that the relatively bulky tangeretin exhibited rather limited access to the progesterone binding site; thus, residues within $5 \AA$ of the bound progesterone were allowed to be flexible for docking all three ligands. An expanded rectangular box $\left(25 \times 25 \times 25 \AA^{3}\right)$ to accommodate all flexible residues was centered around the progesterone $\mathrm{C} 8$ carbon for flexible residue docking. For GR, chain A of the 3E7C crystal structure of the receptor complexed with the agonist GSK866 was used as the receptor, and similarly prepared by MGLTools to add polar hydrogen and charges. A rectangular box of $\left(16 \times 16 \times 18 \AA^{3}\right)$ centered around the N2 atom of the bound GSK866 was used for the ligand exploration region. The more open GR binding site did not hinder docking of any the ligands, making the addition of flexibility unnecessary. All ligands were docked against the respective receptor structures using the Autodock vina program [28]. Figures were prepared with USCF Chimera [29] from the Computer Graphics Laboratory, University of California, San Francisco (supported by NIH P41 RR-01081).

\section{Western Blotting}

T47D cells (400,000 per well) were plated in 6-well plates in RPMI 1640 phenol red-free media supplemented with $10 \%$ charcoal-stripped FBS for $24 \mathrm{~h}$. Cells were treated for $24 \mathrm{~h}$ and lysed in buffer containing RIPA, a phosphatase inhibitor, and a protease inhibitor. BCA was performed to determine protein concentration. Protein lysate $(25 \mu \mathrm{g})$ was run on SDS-PAGE gels by electrophoresis and transferred to a nitrocellulose membrane. Membranes were blocked with $5 \%$ milk in TBST and probed with PR, GR, or $\beta$-actin overnight at $4{ }^{\circ} \mathrm{C}$ (Supplementary Table 1). The next day, membranes were incubated with anti-rabbit secondary antibody (Cell Signaling no. 7074S) and developed with SuperSignal West Femto Substrate (34095, Thermo Scientific, Rockford, IL). Images were captured with a FluorChem C (Protein Simple, San Jose, CA). [16].

\section{Progesterone Receptor Fluorescence Polarization Competitive Binding Assay}

The PolarScreen ${ }^{\mathrm{TM}}$ progesterone receptor fluorescence polarization competitor assay kit, green, was purchased from A15905, Life Technologies, Inc. Carlsbad, CA. The progesterone receptor ligand-binding domain (amino acids 675-933) fused to GST (PR-LBD-GST; $654 \mathrm{nM}$ ), a fluorescently tagged PR ligand (fluoromone green PL; $6.5 \mathrm{nM}$ ), and either progesterone or baicalein was incubated in PR screening buffer with $1 \mathrm{M}$ dithiothreitol (DTT) in a total volume of $80 \mu \mathrm{L}$ for $2 \mathrm{~h}$ at room temperature as described previously [18]. Each sample was analyzed in triplicate using a Synergy Neo2 Hybrid Multi-Mode Reader (Biotek, Winooski, VT). An average of three samples containing only buffer and PR-LBD-GST with no fluorescent PL was used as the blank to eliminate background signal from the protein or buffer. A sample with no competitor was used to determine $100 \%$ binding capacity of the PR-LBD-GST for the fluorescently tagged PR ligand.

\section{Glucocorticoid Receptor Fluorescence Polarization Competitive Binding Assay}

The PolarScreen ${ }^{\mathrm{TM}}$ glucocorticoid receptor fluorescence polarization competitor assay kit, red, was purchased from A15898, Life Technologies, Inc. Carlsbad, CA. Full-length glucocorticoid receptor $(2585 \mathrm{nM})$, a fluorescently tagged GR ligand (fluoromone GS red (1.4 nM)), GR-stabilizing peptide, and either dexamethasone or baicalein were incubated in 
GR screening buffer with 1 M DTT in a total volume of $80 \mu \mathrm{L}$ for $2 \mathrm{~h}$ at room temperature. Each sample was analyzed in triplicate using a SpectraMax i3x with an FP-Rhodamine module plate reader (Molecular Devices, San Jose, CA). An average of three samples containing only buffer and fulllength GR with the stabilizing peptide and no fluoromone GS was used as the blank to eliminate background signal from the protein or buffer. A sample with no competitor was used to determine $100 \%$ binding capacity of the GR for the fluorescently tagged GR ligand.

\section{Quantitative PCR}

Quantitative PCR (qPCR) was used to examine the induction of the glucocorticoid target genes glucocorticoidinduced leucine zipper (GILZ) and FK506 binding protein 5 (FKBP5) after treatment. Primer sequences are found in Supplementary Table 2. OVCAR5 and MDA-MB-231 were used to measure glucocorticoid target gene expression. OVCAR5 $(200,000$ cells/well in 6 well plate) and MDA-MB-231 ( 1 million cells $/ 10 \mathrm{~cm}$ plate) were plated in phenol red-free media. OVCAR5 and MDA-MB-231 cells were plated in phenol red-free media for $48 \mathrm{~h}$ and then treated with pure compounds for $6 \mathrm{~h}$. The cells were washed with PBS and lysed with Trizol (Ambion ${ }^{\mathrm{TM}}$, 15596018, Thermo Scientific, Waltham, MA) and stored at $-80{ }^{\circ} \mathrm{C}$ until extracted for RNA. RNA extraction was performed using Trizol and chloroform with isopropanol precipitation followed by ethanol washes and DNAse I step as previously described [18]. iScript ${ }^{\mathrm{TM}}$ complementary DNA synthesis kit (1708841, Bio-Rad, Hercules, CA) and SYBR green (Applied Biosystems ${ }^{\mathrm{TM}}$, A25780, Thermo Scientific, Waltham, MA) were used according to manufacturer's instructions. qPCR measurements were performed using the CFX Connect Real-Time PCR Detection System (Bio-Rad, Hercules, CA). Samples were normalized to $18 \mathrm{~s}$.

\section{Proliferation Assay}

T47D cells (1000 cells per well) were seeded onto a 96well plate. Cells were allowed to attach for 20 to $24 \mathrm{~h}$. After cells attached, a day 0 plate was collected. Baicalein, progesterone, estradiol, or RU486 were added at indicated concentrations on the remaining plate. Plates were collected at day 9. Half of the media was replaced on day 4 for the day 9 plate. On day of collection, media was removed, and cells were fixed with $20 \%$ trichloroacetic acid (TCA). Proliferation was measured by sulforhodamine B (SRB) as previously described [30]. Fold proliferation values were normalized to day 0 .

\section{Animal Study}

Female (age 6-8 weeks) athymic nude mice were randomly assigned into six different treatment groups with five mice per group. Treatments consisted of intraperitoneal injections of vehicle, $0.1 \mathrm{mg} / \mathrm{kg}$ dexamethasone, $25 \mathrm{mg} / \mathrm{kg}$ baicalein, $15 \mathrm{mg} / \mathrm{kg}$ RU486, $0.1 \mathrm{mg} / \mathrm{kg}$ dexamethasone $+15 \mathrm{mg} / \mathrm{kg}$ RU486, and $25 \mathrm{mg} / \mathrm{kg}$ baicalein + $15 \mathrm{mg} / \mathrm{kg}$ RU486. Dexamethasone, baicalein, and RU486 were dissolved in $10 \%$ DMSO and $90 \%$ sesame oil to form an emulsion. Due to baicalein and RU486 separating from the emulsion, treatments were vortexed for each injection for each animal. Treatments were administered twice a week for about 4 weeks. On the last day of treatment, animals were euthanized by humane means approximately $3 \mathrm{~h}$ after the treatment was administered. Reproductive tracts were excised and fixed in $4 \%$ paraformaldehyde (PFA) for immunohistochemical analysis. The other half of the reproductive tracts were frozen to be used for qPCR analysis. All protocols were approved by University of Illinois at Chicago Animal Care and Use Committee and the Association for the Assessment and Accreditation of Laboratory Animal Care.

\section{RNA Extraction and qPCR of Animal Tissues}

RNA was extracted from the reproductive tracts using RNeasy Mini Kit (no. 74104, Qiagen, Hilden, Germany) following the manufacturer's instructions. The reproductive tracts were homogenized using Zirconia beads (no. NC0450473, Thermo Scientific, Waltham, MA) in $600 \mu \mathrm{L}$ Buffer RLT and Mini BeadBeater. After RNA was extracted from the reproductive tracts, complementary DNA (cDNA) was made using iScript $^{\mathrm{TM}}$ complementary DNA synthesis kit (1708841, BioRad, Hercules, CA) according to the manufacturer's instructions. qPCR was performed for GILZ (Supplementary Table 2). SYBR green (Applied Biosystems ${ }^{\mathrm{TM}}$, A25780, Thermo Scientific, Waltham, MA) was used according to the manufacturer's instructions. qPCR measurements were performed using the CFX Connect Real-Time PCR Detection System (Bio-Rad, Hercules, CA). Samples were normalized to $18 \mathrm{~s}$.

\section{Statistical Analysis}

All data is represented by the mean \pm SEM and replicated at least three times. The data was analyzed by a one-way ANOVA followed by Dunnett's or Tukey's post hoc analysis or Student's $t$ test comparing each treatment to a control group as indicated. $P<0.05$ was considered significant. All analyses were conducted in Prism version 8.2.0. 


\section{Results}

\section{Baicalein Is Predicted to Bind to the Progesterone Receptor}

Based on their structural similarity to the characterized phytoprogestin compounds (apigenin and kaempferol), tangeretin, wogonin, and baicalein were modeled in the binding pocket of PR to determine if they could be predicted to bind to the PR [16-18] (Fig. 1a, b). In addition to structural similarity, a literature search for tangeretin, wogonin, and baicalein suggested they may possess hormone receptormediated activity based on changes to breast cancer cell proliferation and migration [31-39]. Molecular docking studies showed that the top nine docking poses for all three compounds were within the approximate envelope of the native ligand (progesterone). This indicates that all three compounds would likely bind to approximately the same site as progesterone. The Autodock estimated binding free energy for the top scoring ligand poses was similar for all three ligands for each receptor $(-9.1$ to $-9.9 \mathrm{kcal} / \mathrm{mol})$. The methoxy side chains of tangeretin are bulky and show constrained docking poses in the PR (Fig. 1c). Both wogonin and baicalein showed little conformational specificity for the PR. The top two poses for wogonin were flipped both horizontally and vertically (Fig. 1d). The top two poses for baicalein were rotated by nearly $180^{\circ}$ around the vertical axis (Fig. 1e). The added methoxy group of wogonin compared to baicalein provides some modest conformational restriction that is significantly accentuated in tangeretin, where all the hydroxyl groups are methylated. The added conformational bulk of the five methoxy groups in tangeretin results in highly constrained

a<smiles>O=c1cc(-c2ccc(O)cc2)oc2cc(O)cc(O)c12</smiles><smiles>O=c1c(O)c(-c2ccc(O)cc2)oc2cc(O)cc(O)c12</smiles>

Apigenin

Kaempferol

b<smiles>COc1ccc(-c2cc(=O)c3c(OC)c(OC)c(OC)c(OC)c3o2)cc1</smiles><smiles>COc1c(O)cc(O)c2c(=O)cc(-c3ccccc3)oc12</smiles>

Wogonin<smiles>O=c1cc(-c2ccccc2)oc2cc(O)c(O)c(O)c12</smiles>

Baicalein

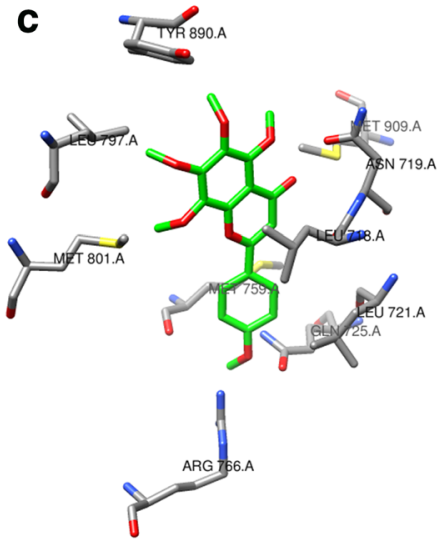

d

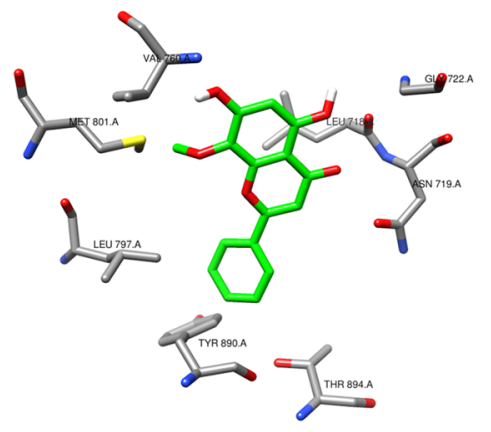

e

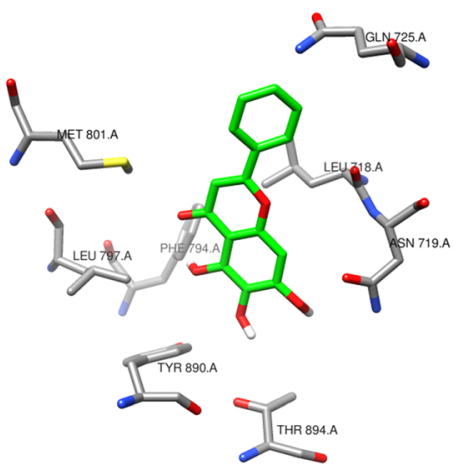

Fig. 1 Baicalein is predicted to bind to PR with little conformational specificity. a Structures of known phytoprogestin compounds, apigenin and kaempferol. b Structures of tangeretin, wogonin, and baicalein which were screened for progestogenic activity. c-e Molecular docking of tangeretin, wogonin, and baicalein with PR, crystal structure PDB ID:1a28. c Top-ranked docking pose for tangeretin with PR, showing side chains of PR residues within $3.5 \AA$ of tangeretin. PR residues include Tyr890, Leu797, Met801, Arg766, Met759, Gln725, Leu718,
Leu719, and Met909. d Top-ranked docking pose for wogonin with PR, showing side chains of PR residues within $3.5 \AA$ of wogonin. PR residues include Va1760, Met801, Leu797, Tyr890, Asn719, Leu718, Gln725, Thr894, and Gly722. e Top-ranked docking pose for baicalein with PR, showing side chains of PR residues within $3.5 \AA$ of Baicalein. PR residues include Met801, Leu797, Phe794, Asn719, Leu718, Gln725, Thr890, and Thr894 
binding for tangeretin in PR. Overall, this suggests that baicalein and wogonin bind to PR primarily through relatively non-specific hydrophobic interactions that allow the ligands to assume a variety of potential binding poses, and with no potential hydrogen bonds observed that could constrain binding poses.

\section{Expression of PR and GR in Ishikawa, T47D, OVCAR5, and MDA-MB-231 Cells}

Ligands for PR are often ligands for other steroid receptors, particularly GR [26]. Western blotting was used to identify cell models that expressed PR or GR (Supplementary Fig. 1a). A variant of the Ishikawa cells, which are an endometrial cancer cell line that expresses no PR (Ishikawa null) and negligible GR, was engineered to express PR-B [25]. PR expression in Ishikawa PR-B cells was validated via western blot (Supplementary Fig. 1a). T47D is a breast cancer cell line that was shown to have high expression of both PR isoforms, PR-B and PR-A, and low levels of GR. The ovarian cancer cell line, OVCAR5, and the triple-negative breast cancer cell line, MDA-MB-231, did not express PR but both express GR (Supplementary Fig. 1a, b). Interestingly, Ishikawa PR-B expresses high levels of GR (Supplementary Fig. 1b).

\section{Baicalein Is a Progesterone Receptor Antagonist}

Tangeretin, wogonin, and baicalein were each modeled to have some poses that should bind to the PR, with baicalein potentially being a better PR ligand than the other two compounds. To determine if tangeretin, wogonin, and baicalein have PR activity, a hormone response element (HRE)/luciferase (Luc) assay was performed in Ishikawa PR-B cells. Since progesterone binds exclusively to PR, the assay determined whether tangeretin, wogonin, and baicalein were progesteronelike compounds. Tangeretin did not induce basal luciferase activity by itself at the indicated concentrations, nor did it antagonize progesterone (100 nM) (Fig. 2a, b). Similarly, wogonin did not induce basal luciferase activity by itself or antagonize progesterone (100 nM) (Fig. 2c, d). Baicalein did not induce basal luciferase activity by itself (Fig. 1e), but when combined with progesterone $(100 \mathrm{nM})$, baicalein antagonized progesterone activity at 5 and $10 \mu \mathrm{M}(P<0.05$ and $P<0.01$ respectively, Fig. 1f). Baicalein was the only compound to have significant progesterone-like activity. Therefore, a fluorescence polarization competitive binding assay was conducted. Progesterone bound to $\mathrm{PR}$ with an $\mathrm{IC}_{50}$ of $1.2 \mu \mathrm{M}$ in the competitive binding assay. The competitive binding assay confirmed the docking studies that baicalein bound to $\mathrm{PR}$ with an $\mathrm{IC}_{50}$ of $15.30 \mu \mathrm{M}$. (Fig. $2 \mathrm{~g}$ ).

\section{Baicalein Acted as a Progesterone Receptor Antagonist with No Effect on Breast Cancer Cell Proliferation}

T47D cells are a breast cancer cell line that endogenously expresses PR-B, PR-A, and low levels of GR, and they were used to confirm that baicalein antagonized PR activity. Baicalein by itself did not induce luciferase activity and actually reduced basal luciferase activity in T47D cells at 5 and $10 \mu \mathrm{M}(P<0.001$, Fig. 3a). In combination with progesterone $(100 \mathrm{nM})$, baicalein $(5$ and $10 \mu \mathrm{M})$ antagonized progesterone luciferase activity $(P<0.05$ and $P<0.01$, Fig. $3 b)$. Upon binding to $\mathrm{PR}$, progesterone is known to stimulate degradation of PR after transcriptional activation of target genes as part of a negative feedback loop [1]. To determine if baicalein induced degradation of PR, a western blot was performed using T47D cells. Baicalein did not induce degradation of PR at any of the doses tested, unlike the positive control, progesterone $(100 \mathrm{nM})$ (Fig. 3c, d). Next, qPCR was performed in T47D cells for the PR gene, TRIM22. Progesterone (100 nM) induced TRIM22 20-fold, and this effect was blocked by the antagonist RU486 $(1 \mu \mathrm{M})$. Baicalein $(10 \mu \mathrm{M})$ induced TRIM22 2-fold and when combined with $100 \mathrm{nM}$ progesterone, baicalein was not able to significantly repress progesterone-induced expression of TRIM22 (Fig. 3e). Next, baicalein's capacity to affect proliferation of T47D cells was investigated. Baicalein has previously been shown to inhibit proliferation of MCF7 breast cancer cells in the absence and presence of estradiol $[35,38]$. Baicalein did not have an effect on proliferation in T47D cells over 9 days (Fig. 3f). 17 $\beta$ estradiol (E2) induces proliferation of T47D cells at 1 and $10 \mathrm{nM}(P<0.05$, Supplementary Fig. 2a). High-dose progesterone $(10 \mu \mathrm{M})$ inhibits proliferation of T47D cells, but low doses did not significantly inhibit T47D cells $(P<0.05$, Supplementary Fig. $2 \mathrm{~b})$. When E2 $(1 \mathrm{nM})$ and progesterone were combined, progesterone inhibited E2-induced proliferation of T47D cells in a dose-dependent manner $(P<0.05$, Fig. $3 \mathrm{~g})$. Baicalein was combined with $\mathrm{E} 2(1 \mathrm{nM})$ to determine if it could behave like a progestin and inhibit E2-induced proliferation of T47D cells. Baicalein did not inhibit E2-induced proliferation of T47D cells (Fig. 3h).

\section{Baicalein Acts as a Glucocorticoid Agonist}

Synthetic PR ligands often typically bind to GR. To determine if baicalein, wogonin, and tangeretin also bound to the GR, molecular docking studies were performed with the three compounds in the binding pocket of the GR. The top nine docking poses for all three ligands were within the approximate envelope of the native ligand (GSK866), indicating that they all bind in approximately the same site as GSK866. The Autodock estimated binding-free energies for the top-scoring ligand poses were similar for all three ligands $(-8.4$ to - 

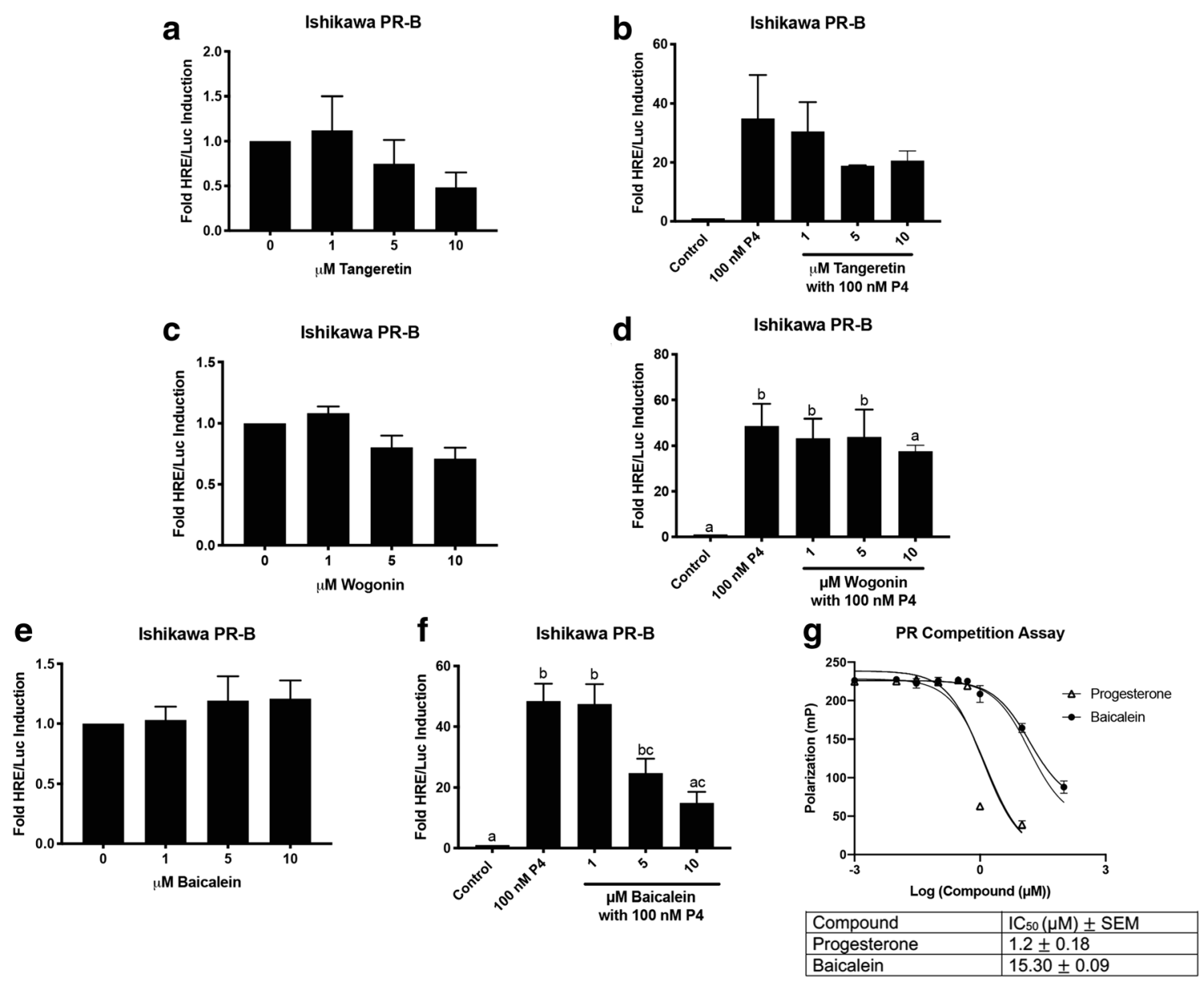

Fig. 2 Baicalein is a PR antagonist in Ishikawa PR-B cells. a HRE/Luc of tangeretin alone. b HRE/Luc of tangeretin with $100 \mathrm{nM}$ progesterone (P4). c HRE/Luc of wogonin alone. d HRE/Luc of wogonin with $100 \mathrm{nM}$ P4. e HRE/Luc of baicalein alone. $\mathbf{f ~ H R E / L u c ~ o f ~ b a i c a l e i n ~ w i t h ~}$

$8.9 \mathrm{kcal} / \mathrm{mol})$. Tangeretin also showed conformational restriction for the GR due to its bulky methoxy groups, with the top docking poses maintaining the same basic orientation and only displaced by approximately the width of the one aromatic ring. Tangeretin potentially forms one hydrogen bond in the GR binding site. (Fig. 4a). Wogonin exhibits fewer stabilizing interactions with the GR binding site than tangeretin, as no potential hydrogen bonds are observed with wogonin in the GR binding site. The added methoxy group for wogonin appears to restrict binding with the top docking poses flipped horizontally and only partially displaced vertically (Fig. 4b). Baicalein exhibits more stabilizing interactions in the GR binding site, as more hydrogen bonds are able to form with baicalein in the GR binding site. Baicalein shows essentially no binding site conformational specificity, with the top two docking poses inverted and displaced vertically almost the full length of the molecule (Fig. 4c).

To confirm the GR activity of the compounds, a luciferase assay was performed in OVCAR5 cells, which express GR but not PR (Supplementary Fig. 1). Tangeretin $(10 \mu \mathrm{M})$
$100 \mathrm{nM}$ P4. g Fluorescence polarization competitive binding assay for the $\mathrm{PR}$ with progesterone and baicalein. $\mathrm{N} \geq 3$. Data represent mean $\pm \mathrm{SEM}$. Significantly different from $0 \mu \mathrm{M}$ or control. $* P<0.05 ; * * P<0.01$. Bars without common letter are significantly different. ${ }^{\mathrm{a}-\mathrm{c}} \mathrm{P}<0.05$

induced luciferase activity 1.5 -fold $(P<0.05$, Fig. 4 d). In combination with $100 \mathrm{nM}$ dexamethasone, tangeretin $(10 \mu \mathrm{M})$ induced luciferase activity 7 -fold $(\mathrm{P}<0.05$, Fig. $4 \mathrm{e})$. Wogonin did not induce luciferase activity, nor did it antagonize dexamethasone-induced luciferase activity (Fig. 4f, g). Baicalein (5 and $10 \mu \mathrm{M})$ significantly induced basal luciferase activity $2-$ and 4 -fold, respectively $(P<0.05$ and $P<0.001$; Fig. 4h). Baicalein was combined with the glucocorticoid agonist, dexamethasone, to determine if baicalein acted as an antagonist. Baicalein $(5$ and $10 \mu \mathrm{M})$ reduced dexamethasone-induced luciferase activity from 12 -fold to 7-fold. This indicates that baicalein is acting as a partial agonist in OVCAR5 cells (Fig. 4i). Of these compounds, baicalein induced the most GR activity. The GR activity of baicalein was evaluated in another cell line, MDA-MB-231, which does not contain PR but does contain GR (Supplementary Fig. 1a-b). Baicalein $(5$ and $10 \mu \mathrm{M})$ induced luciferase activity in MDA-MB-231 cells 4- and 7-fold, respectively $(P<0.01$ and $P<0.001$, Supplementary Fig. 3a). Baicalein also reduced dexamethasone-induced luciferase 

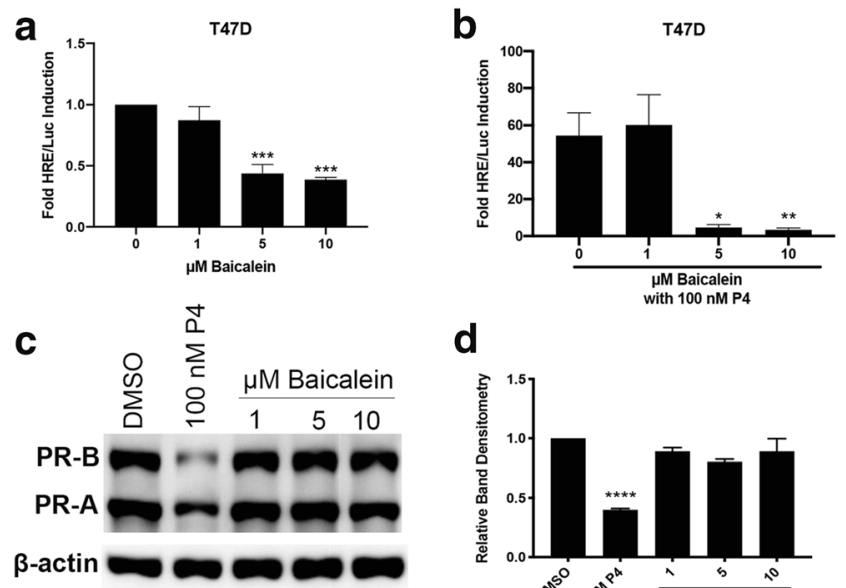

d
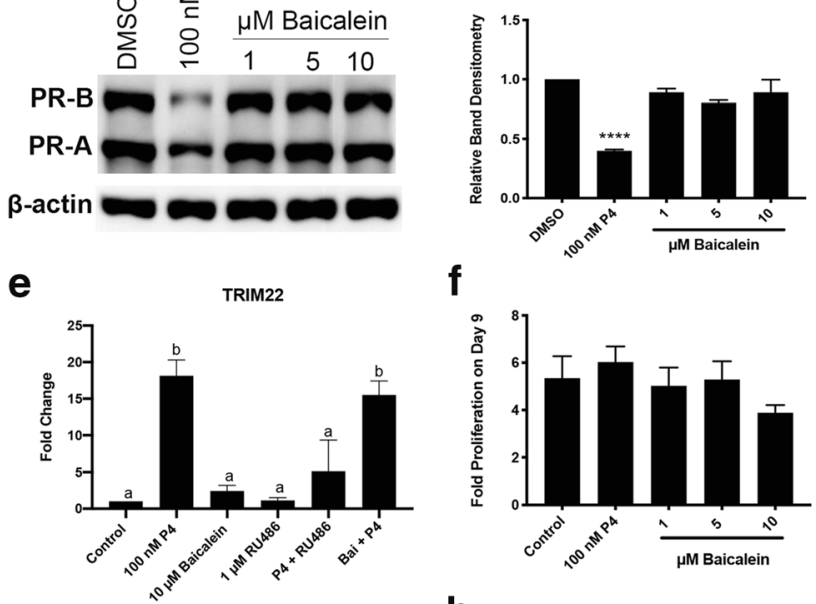

g

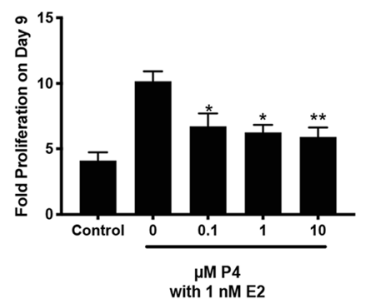

$\mathrm{h}$
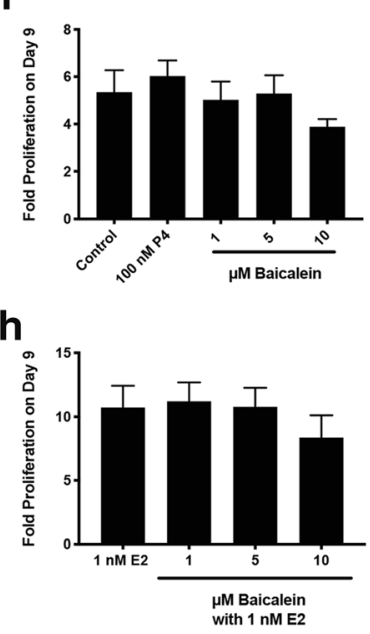

Fig. 3 Baicalein is a PR antagonist in T47D cells without reducing T47D cell proliferation. a HRE/Luciferase activity of baicalein alone. b HRE/ Luciferase activity of baicalein in combination with $100 \mathrm{nM}$ P4. c Representative western blot for PR-B and PR-A levels in T47D cells treated with $100 \mathrm{nM}$ P4 or baicalein for $24 \mathrm{~h}$. d Densitometry of total PR levels in T47D cells after P4 or baicalein treatment. e qPCR of TRIM22 in T47D cells after treatment with P4 (100 nM), RU486 $(1 \mu \mathrm{M})$ and baicalein $(10 \mu \mathrm{M})$ as indicated. f Proliferation of T47D cells after treatment with P4 or baicalein. g Proliferation of T47D cells after treatment with E2 and P4 as indicated. h Proliferation of T47D cells after treatment with $\mathrm{E} 2$ and baicalein as indicated. $\mathrm{N} \geq 3$. Data represent mean \pm SEM. Significantly different from $0 \mu \mathrm{M}$ or Control. $* P<0.05$; $* * P<0.01 ; * * * P<0.001$

activity from 12 -fold to 7 -fold in MDA-MB-231 cells (Supplementary Fig. 3b), suggesting baicalein is acting as a partial agonist.

\section{Baicalein Binds to the Glucocorticoid Receptor and Induces Glucocorticoid Receptor Responsive Genes}

To determine if baicalein could bind to the GR, a fluorescence polarization competitive binding assay for the GR was performed. Dexamethasone bound to GR with an $\mathrm{IC}_{50}$ of $0.07 \mu \mathrm{M}$. Baicalein bound to the GR with an $\mathrm{IC}_{50}$ of $19.26 \mu \mathrm{M}$ (Fig. 5a). Baicalein induced HRE/Luc activity (Fig. 4h) in OVCAR5 cells, which lack PR and only express GR. To confirm whether baicalein's luciferase activity is mediated through the GR, RU486 was combined with baicalein. In OVCAR5 cells, RU486 $(1 \mu \mathrm{M})$ blocked dexamethasone luciferase induction $(P<0.05$, Fig. $5 b)$. RU486 $(1 \mu \mathrm{M})$ also blocked baicalein's luciferase induction $(P<0.05$ Fig. $5 \mathrm{c})$. This, along with the fluorescence polarization assay, confirms that baicalein mediates its effect in OVCAR5 through the GR. Next, qPCR was performed for GR-responsive genes GILZ and FKBP5 in OVCAR5 and MDA-MB-231 cells to further verify the GR agonist activity of baicalein. Dexamethasone $(30 \mathrm{nM})$ induced GILZ 40-fold in OVCAR5 cells, and this effect was abrogated by RU486 $(P<0.001$ Fig. 5 d). Baicalein $(10 \mu \mathrm{M})$ induced GILZ 25-fold in OVCAR5 cells, and the induction was inhibited by RU486 $(P<0.01$ Fig. 5 e). A similar effect was shown for the gene FKBP5. Dexamethasone $(30 \mathrm{nM})$ induced FKBP5 10-fold, and RU486 blocked dexamethasone's induction of FKBP5 $(P<0.05$, Fig. 5f). Baicalein $(10 \mu \mathrm{M})$ induced FKBP5 expression 25-fold, and RU486 blocked baicalein's induction of FKBP5 ( $P<0.01$ Fig. $5 \mathrm{~g}$ ). In MDA-MB-231 cells, dexamethasone $(30 \mathrm{nM})$ induced GILZ 25-fold $(P<0.01$, Supplementary Fig. 3c). Baicalein $(5 \mu \mathrm{M})$ induced GILZ 3-fold $(P<0.05$, Supplementary Fig. 3d). For FKBP5, dexamethasone (30 nM) induced FKBP5 4-fold $(P<0.01$, Supplementary Fig. 3e). Baicalein $(5$ and $10 \mu \mathrm{M})$ did not significantly induce FKBP5 in MDA-MB-231 cells (Supplementary Fig. 3f).

Next, baicalein's ability to affect proliferation in OVCAR5 cells was investigated. Dexamethasone $(100 \mathrm{nM})$ was found to reduce proliferation of OVCAR5 cells over 4 days $(P<0.05$, Fig. 5 h $)$. Baicalein $(10 \mu \mathrm{M})$ was also able to reduce proliferation of OVCAR5 cells over 4 days $(P<0.01$, Fig. $5 \mathrm{~h})$. To determine if the ability of baicalein to reduce proliferation of OVCAR5 cells was through the GR, RU486 $(1 \mu \mathrm{M})$ was combined with baicalein $(10 \mu \mathrm{M})$. RU486 was not able to reverse the anti-proliferative effects of baicalein, indicating that baicalein's anti-proliferative effect in OVCAR5 cells is likely independent of GR $(P<0.05$, Fig. 5 i) .

\section{Baicalein Induces Expression of the GR Target Gene GILZ in Vivo}

Female nude mice (30 mice total) were treated with compounds dissolved in 10\% DMSO and 90\% sesame oil twice per week for 4 weeks, which was tolerated by the animals. The reproductive tracts were collected $3 \mathrm{~h}$ after the last injection and used to determine if baicalein could induce GR signaling in vivo. qPCR was performed for the GR-responsive gene GILZ. Dexamethasone $(0.1 \mathrm{mg} / \mathrm{kg})$ induced GILZ 6-fold, which was blocked by the antagonist RU486 $(15 \mathrm{mg} / \mathrm{kg})$ $(P<0.05$, Fig. 6a). Baicalein $(25 \mathrm{mg} / \mathrm{kg})$ induced GILZ 3- 
a

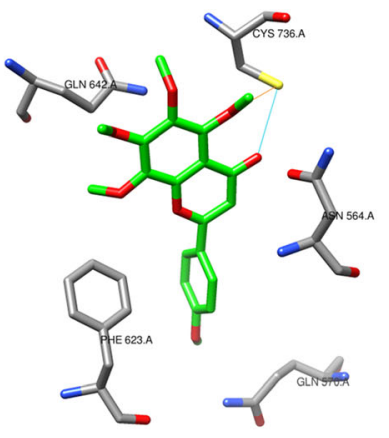

d

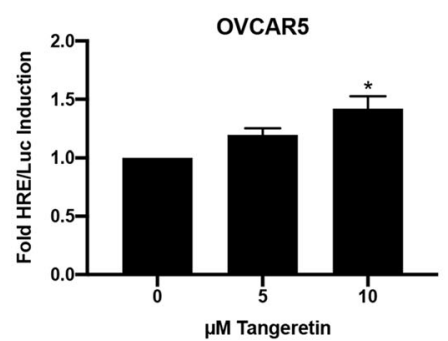

g

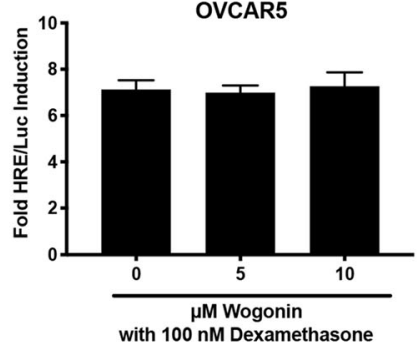

b

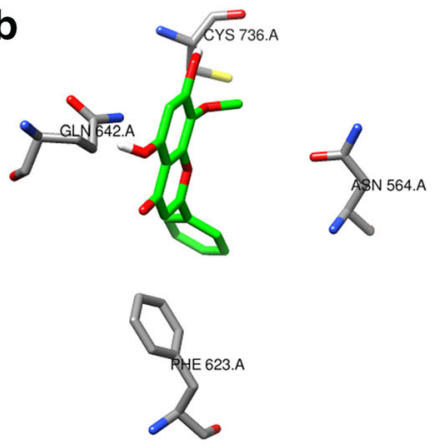

e

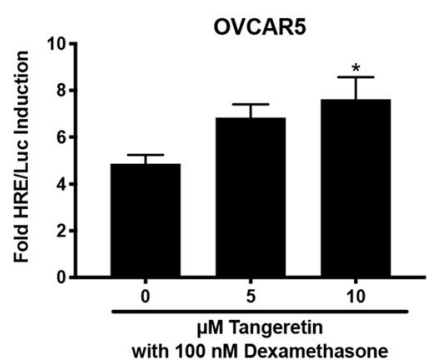

h

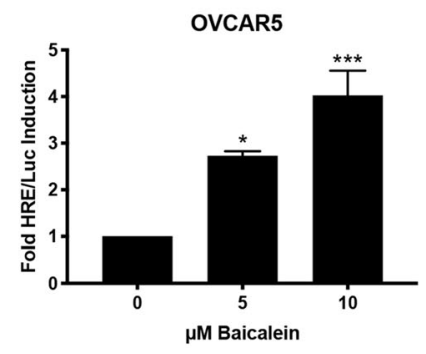

C

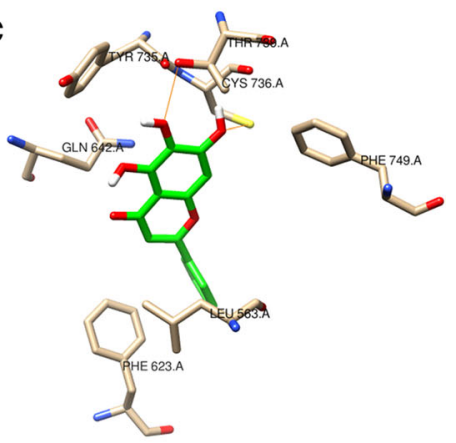

f

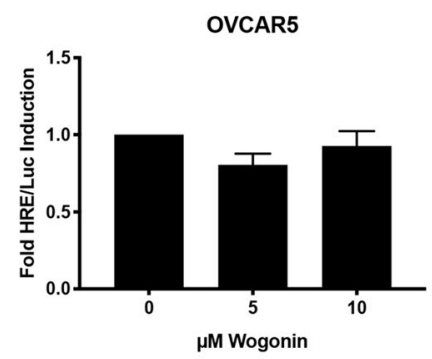

i

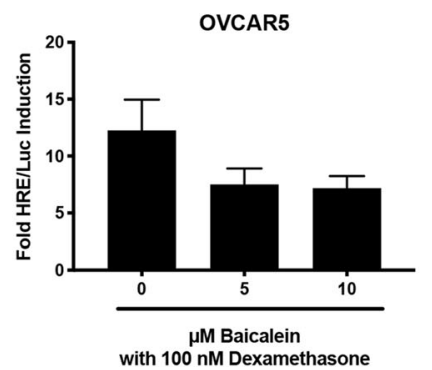

Fig. 4 Baicalein is a glucocorticoid agonist in OVCAR5. a-c Molecular docking of tangeretin, wogonin, and baicalein with GR, crystal structure PDB ID:3e7c. a Top-ranked docking pose for tangeretin with GR, showing side chains of GR residues within $3.5 \AA$ of tangeretin. GR residues include Cys736, Gln642, Phe623, Gln570, and Asn564. Potential hydrogen bond interactions are shown as dashed lines. b Topranked docking pose for wogonin with GR, showing side chains of GR residues within $4.0 \AA$ of wogonin. GR residues include Cys736, Gln642, Phe623, and Asn564. c Top-ranked docking pose for baicalein with GR,

fold and RU486 $(15 \mathrm{mg} / \mathrm{kg})$ blocked baicalein's induction of GILZ $(P<0.05$, Fig. 6b). Baicalein activated expression of a glucocorticoid target gene in vivo which was blocked by the inhibitor, RU486.

\section{Discussion}

Baicalein is a flavonoid from Scutellaria baicalensis (Chinese skullcap) that was shown in this report to have both PR and GR activity. Baicalein acts as a PR antagonist and as a GR agonist. Baicalein binds to both receptors with little conformational specificity and with roughly the same binding affinity for both receptors. Baicalein does not induce PR degradation nor does it affect proliferation of T47D breast cancer cells showing side chains of GR residues within $3.5 \AA$ of baicalein. GR residues include Thr780, Cys736, Tyr735, Gln642, Phe623, Leu563, and Phe749. Potential hydrogen bond interactions are shown as dashed lines. d-i HRE/Luc of tangeretin $(\mathbf{d}, \mathbf{e})$, wogonin $(\mathbf{f}, \mathbf{g})$, and baicalein $(\mathbf{h}, \mathbf{i})$ in OVCAR 5 cells alone or in combination with $100 \mathrm{nM}$ dexamethasone. $\mathrm{N} \geq 3$. Data represent mean \pm SEM. Significantly different from $0 \mu \mathrm{M}$ or control. $* P<0.05 ; * * P<0.01$; $* * * P<0.001$. Bars without common letter are significantly different ${ }^{\mathrm{a}-\mathrm{b}} P<0.05$

alone or in combination with E2. GR genes are upregulated by baicalein in vitro and in vivo. The dual activity of baicalein on the PR and GR could be promising for patients who have inflammatory gynecological diseases that need to be treated with a progestin antagonist, as baicalein could confer both benefits: reducing inflammation through the GR and functioning as a PR antagonist. However, patients that would benefit from a PR and GR agonist might see negative effects from blocking PR action.

The synthetic progestins medroxyprogesterone acetate and norethisterone acetate were found to have high relative binding affinity for the PR, AR, and GR [9, 40]. Progesterone agonists medroxyprogesterone acetate, norethisterone acetate, and levonorgestrel have both PR agonist and GR agonist activities. The PR antagonists 

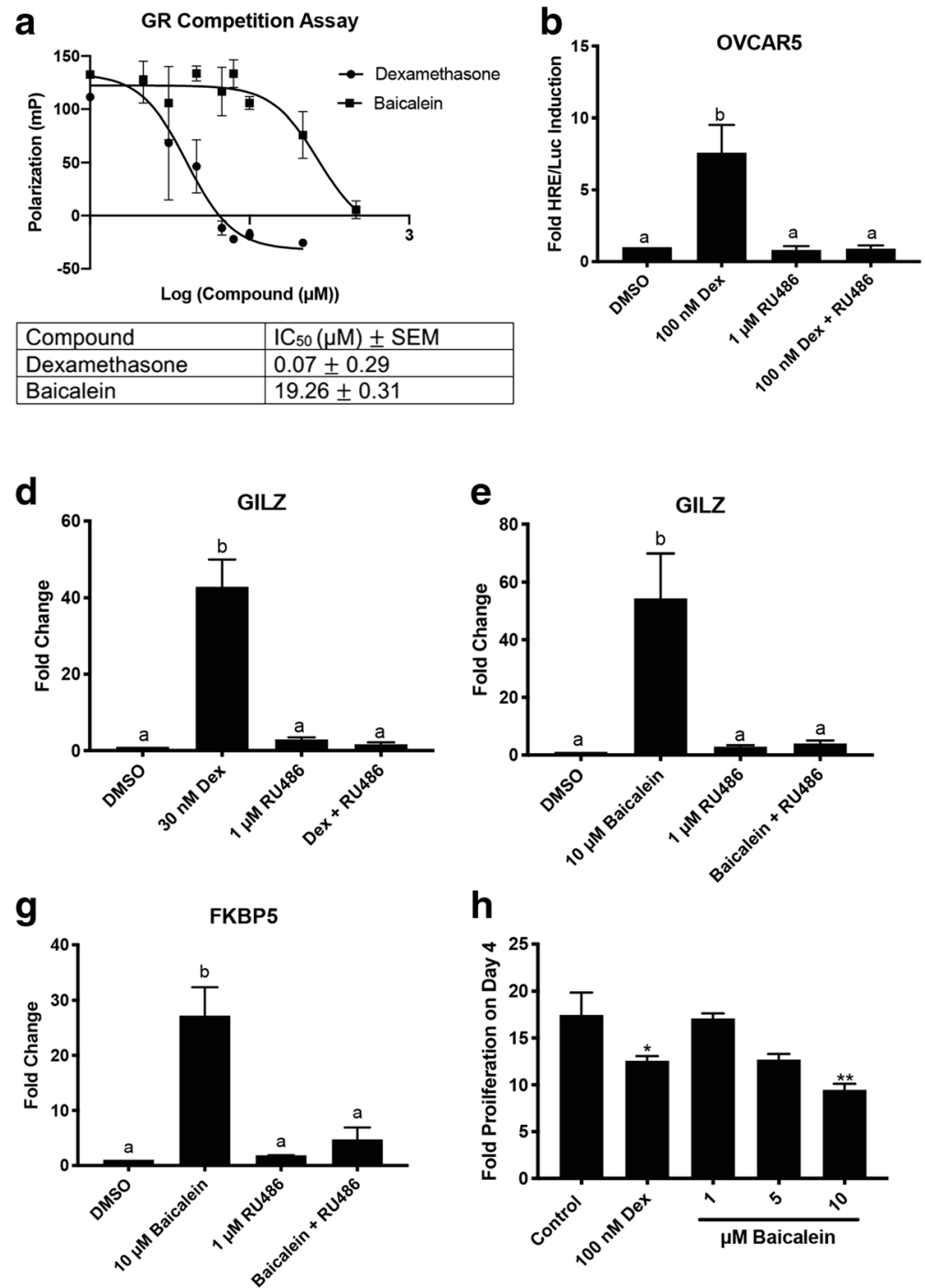
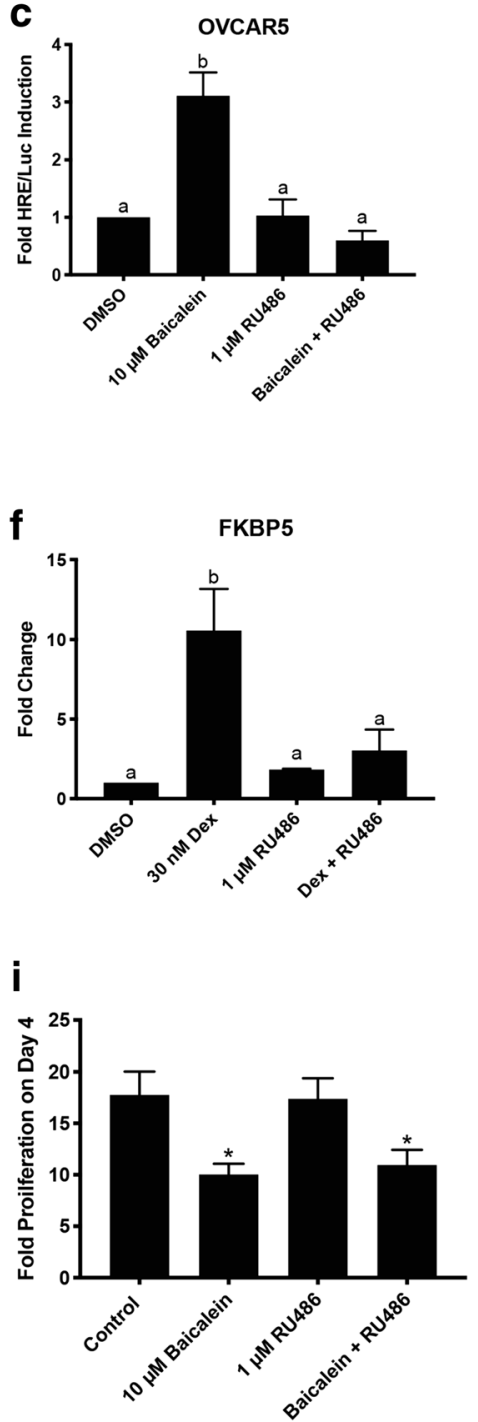

Fig. 5 Baicalein binds to GR and induces GR responsive genes. a Fluorescence polarization competitive binding assay for the GR with dexamethasone and baicalein. b HRE/Luc in OVCAR5 cells with $100 \mathrm{nM}$ dexamethasone (Dex) and $1 \mu \mathrm{M}$ RU486. c HRE/Luc in OVCAR5 cells with $10 \mu \mathrm{M}$ baicalein and $1 \mu \mathrm{M}$ RU486. d qPCR of GILZ in OVCAR5 cells treated with $30 \mathrm{nM}$ dexamethasone or $1 \mu \mathrm{M}$ RU486 for 6 h. e qPCR of GILZ in OVCAR5 cells treated with $10 \mu \mathrm{M}$ baicalein or $1 \mu \mathrm{M}$ RU486 for $6 \mathrm{~h}$. f qPCR of FKBP5 in OVCAR5 cells

RU486, onapristone, and ulipristal acetate have GR antagonist activity. Intriguingly, baicalein seems to exhibit PR antagonist action in cells that have both PR and GR, but when PR is absent, GR activation was found. This type of activity could be beneficial for women who have gynecological diseases that involve inflammation and are treated with progestin antagonists, examples of which include uterine fibroids and endometriosis [41, 42]. Uterine fibroids and endometriosis have inflammatory signatures which contribute to the pain that many women experience with these conditions $[43,44]$. Baicalein has potential to help women with uterine fibroids and endometriosis, as a treated with $30 \mathrm{nM}$ dexamethasone or $1 \mu \mathrm{M}$ RU486 for $6 \mathrm{~h}$. g qPCR of FKBP5 in OVCAR5 cells treated with $10 \mu \mathrm{M}$ baicalein or $1 \mu \mathrm{M}$ RU486 for $6 \mathrm{~h}$. h Proliferation of OVCAR5 cells after treatment with dexamethasone (dex) or baicalein. i Proliferation of OVCAR5 cells after treatment with baicalein and RU486 as indicated. $\mathrm{N} \geq 3$. Data represent mean \pm SEM. Significantly different from $0 \mu \mathrm{M}$ or control. Bars without common letter are significantly different ${ }^{\mathrm{a}-\mathrm{b}} P<0.05$

$\mathrm{PR}$ antagonist to reduce the uterine proliferation and as a GR agonist to reduce inflammation.

Tangeretin, wogonin, and baicalein were all modeled in the binding site of PR and GR, with baicalein predicted to have better binding to both receptors due to less constrained binding poses. The added methoxy groups on wogonin and tangeretin caused the ligands to have constrained binding with both PR and GR. Even though wogonin has no GR activity, previous studies have demonstrated that wogonin has immunosuppressive effects but does not affect the antiinflammatory effect of dexamethasone [45]. Baicalein has no methoxy groups on its structure allowing it to bind to both 


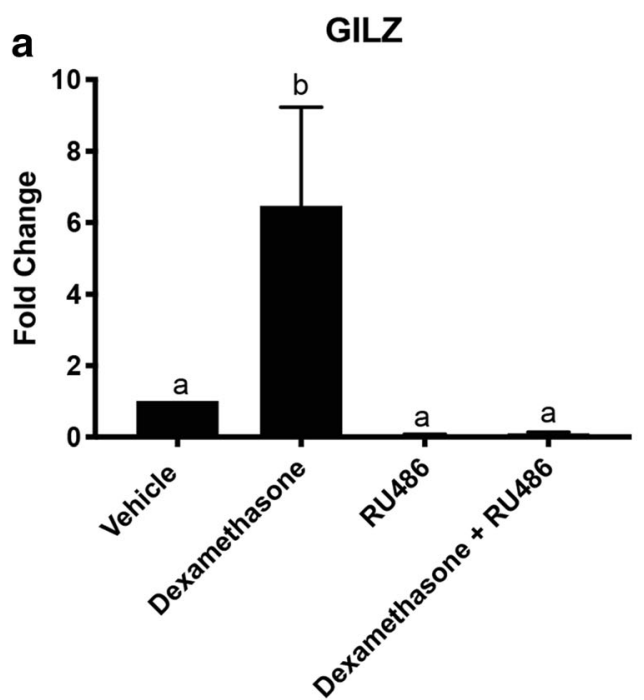

Fig. 6 Baicalein induces GILZ in vivo. qPCR of GILZ from RNA extracted from the uterus of mice treated with dexamethasone, RU486, baicalein, dexamethasone + RU486, and baicalein + RU486. a qPCR of GILZ with dexamethasone $(0.1 \mathrm{mg} / \mathrm{kg}), \mathrm{RU} 486(15 \mathrm{mg} / \mathrm{kg})$, and dexamethasone $(0.1 \mathrm{mg} / \mathrm{kg})+\mathrm{RU} 486(15 \mathrm{mg} / \mathrm{kg})$ treated mice. $\mathbf{b}$ qPCR

receptors without constrained binding and assume a variety of binding poses. This was further seen in the in vitro luciferase data, as baicalein was the only compound to have PRmediated luciferase induction. For the GR, baicalein exhibited agonist activity and tangeretin showed additive activity. GR has a larger binding pocket than PR, which reduces tangeretin's conformational restriction. Unlike for the PR, the GR binding pocket can be expanded to allow ligands to bind, which would allow for bulkier, more functionalized ligands like tangeretin to bind [46]. Few botanical compounds have been studied for their activity on GR. Compound A comes from the plant Salsola tuberculatiformis Botschantzev and is a selective glucocorticoid receptor modulator [24]. Ginseng is another botanical supplement that contains compounds that have potential GR activity $[47,48]$. Here, we have a third plant-derived compound, baicalein, which binds to the GR and induces GR signaling. It is possible that there are many other botanical supplements that bind to the GR and exert anti-inflammatory properties through the GR. As the sales of herbal supplements increase every year, so do the sales of supplements that claim to modulate the immune system [11]. Understanding whether these supplements and the main compounds within them are activating the GR is important for patients who routinely take them.

Baicalein has PR antagonist activity and GR agonist activity in cell lines that only express one of the receptors. In Ishikawa PR-B, a cell line that contains both PR and GR, baicalein behaves as a PR antagonist and does not demonstrate GR agonist activity. By itself, baicalein does not induce luciferase, indicating that it is not demonstrating GR agonist activity. Baicalein binds with about the same binding affinity

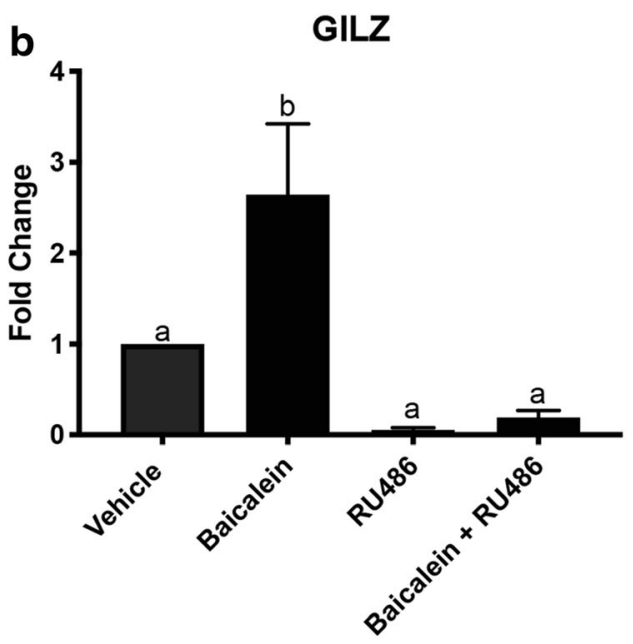

of GILZ with baicalein ( $25 \mathrm{mg} / \mathrm{kg})$, RU486 (15 mg/kg), and baicalein $(25 \mathrm{mg} / \mathrm{kg})+\mathrm{RU} 486(15 \mathrm{mg} / \mathrm{kg})$ treated mice. $\mathrm{N} \geq 3$. Data represent mean \pm SEM. Significantly different from $0 \mu \mathrm{M}$ or control. Bars without common letter are significantly different ${ }^{\mathrm{a}-\mathrm{b}} P<0.05$

for both receptors. This occurrence in a cell line that contains both receptors could be due to the coactivators that are expressed in Ishikawa PR-B cells. There are coactivators that preferentially bind to GR and coactivators that preferentially bind to PR. Steroid receptor coactivator 1 (SRC-1) and SRC-2 are examples of coactivators that bind to either GR or PR. SRC-1 mainly binds to PR and SRC-2 mainly binds to GR [49]. It is possible that in Ishikawa PR-B cells, there is higher expression of SRC-1 than SRC-2, so that when baicalein binds, only PR is being activated and therefore only the PR antagonist activity of baicalein is being expressed. Crosstalk between PR and GR is not well studied and may provide specific signaling in tissue expressing both receptors. Further studies elucidating PR and GR crosstalk could be useful since many PR ligands are known to bind to GR.

GR is a ubiquitous receptor that is found in many cell lines, and many of the cell models used here contained GR. Fluorescence polarization assays confirmed that baicalein bound to both PR and GR and that the induction of GR target genes by baicalein occurred through the GR. RU486 was used to confirm baicalein's activity was mediated by GR. RU486 significantly blocked the induction of luciferase and GR target genes by baicalein indicating that baicalein exerted its effects through GR. The GR activity of baicalein was assessed in cell lines that only contained GR. To further confirm the PR activity, T47D cells were used, which express low amounts of GR. Only high amounts of glucocorticoids induce luciferase activity of T47D cells, as only $10 \mu \mathrm{M}$ dexamethasone induced T47D luciferase activity (data not shown). This indicates that T47D cells do not respond well to glucocorticoids, so that the activity observed in T47D cells is likely mediated by the PR. 
Baicalein was not able to antagonize progesterone at an endogenous gene promoter, TRIM22, in T47D cells (Fig. 3e). Ogara et al. has demonstrated that liganded and unliganded GR can have an antagonistic effect on PR on some promoters in T47D cells [50]. It is possible that baicalein is not having an antagonistic effect on the endogenous gene promoter in T47D cells because there is not enough of the GR for baicalein to elicit its antagonistic effect at this gene promoter. Only one cell model that was used had high amounts of both receptors (Ishikawa PR-B), and the activity that was seen in that model was further confirmed through other cell models. Ishikawa null is the parental cell line that Ishikawa PR-B cells were made from. Ishikawa null lost expression of PR and also does not have GR (Supplementary Fig. 1b) [22]. Since Ishikawa PR-B cells do contain GR, it is possible that the Ishikawa null cells used for the western blot validation of the steroid receptors have also lost expression of GR. At the time the Ishikawa null cells were engineered to express PR, they also could have had GR, but over time, they lost their GR expression.

Baicalein is a major component and one of the bioactive flavonoids of Scutellaria baicalensis (Chinese skullcap). Baicalein represents $5.19-14.24 \%$ of Chinese skullcap extracts, and previous studies have shown it to have anticancer and anti-inflammatory activities [51-57]. Due to its more hydrophilic structure, baicalein can be taken orally. Studies have shown that baicalein is rapidly metabolized by the liver and stomach into its glucuronide form, baicalin. The maximum plasma concentrations of baicalein are achieved between 0.75 and $3 \mathrm{~h}$, depending on the orally administered dose [58]. In a multiple dose study where baicalein was administered to patients twice a day every day for 10 days, it was found that baicalein did not accumulate in the body and was mainly excreted as a metabolite in urine and feces [59]. Animal studies have shown that baicalein is mainly converted to its metabolite, baicalin, in the liver and stomach through glucuronidation and that this metabolite is mainly in systemic circulation $[60,61]$. Since baicalein can be taken orally, the safety is important. Baicalein has been found to exert minimum adverse effects when administered twice daily with increasing doses indicating that it is relatively safe and has low toxicity [59]. There are no reported side effects with Scutellaria baicalensis that are similar to glucocorticoid therapy side effects $[62,63]$. This indicates that Chinese skullcap could potentially be a rather safe glucocorticoid-like extract, although more studies would need to be conducted.

In conclusion, baicalein is a PR antagonist and a GR agonist. Baicalein binds to both receptors with approximately the same binding affinity and is predicted to bind with little conformational specificity to both receptors. Baicalein does not affect breast cancer cell proliferation and induces GR target genes in vitro and in vivo. Furthermore, baicalein's PR antagonist and GR agonist activity could be relevant for women who have gynecological diseases and inflammatory symptoms, as baicalein could signal through the PR and GR. Considering the overlap between PR and GR signaling evidenced here by baicalein, more research is warranted surrounding botanical supplements and their binding to the GR, since many previously discovered ligands for PR and AR may also bind to GR.

Acknowledgements We would like to thank Gregory Thatcher for the use of the Synergy Neo2 Hybrid Multi-Mode Reader and Leslie Aldrich for the use of the SpectraMax i3x with an FP-Rhodamine module plate reader.

Funding Information This work was supported by RO1 AT008824 to JEB and T32 AT007533 supporting JRA from the National Center for Complementary and Integrative Health.

\section{Compliance with Ethical Standards}

All protocols were approved by University of Illinois at Chicago Animal Care and Use Committee and the Association for the Assessment and Accreditation of Laboratory Animal Care.

Conflict of Interest The authors declare they have no conflict of interest.

\section{References}

1. Diep CH, Daniel AR, Mauro LJ et al (2015) Progesterone action in breast, uterine, and ovarian cancers. J Mol Endocrinol 54:R31R53. https://doi.org/10.1530/JME-14-0252

2. Kim JJ, Chapman-Davis E (2010) Role of progesterone in endometrial cancer. Semin Reprod Med 28:81-90. https://doi.org/10.1055/ S-0029-1242998

3. Greenblatt RB, Gambrell RD, Stoddard LD (1982) The protective role of progesterone in the prevention of endometrial cancer. Pathol Res Pract 174:297-318

4. Carroll JS, Hickey TE, Tarulli GA et al (2017) Deciphering the divergent roles of progestogens in breast cancer. Nat Rev Cancer 17:54-64. https://doi.org/10.1038/nrc.2016.116

5. Kim JJ, Kurita T, Bulun SE (2013) Progesterone action in endometrial cancer, endometriosis, uterine fibroids, and breast cancer. Endocr Rev 34:130-162. https://doi.org/10.1210/er.2012-1043

6. Collaborative Group on Epidemiological Studies of Ovarian Cancer, Beral V, Doll R et al (2008) Ovarian cancer and oral contraceptives: collaborative reanalysis of data from 45 epidemiological studies including 23,257 women with ovarian cancer and 87 , 303 controls. Lancet 371:303-314. https://doi.org/10.1016/S01406736(08)60167-1

7. Whiteman DC, Murphy MFG, Cook LS et al (2000) Multiple births and risk of epithelial ovarian cancer. J Natl Cancer Inst 92:11721177. https://doi.org/10.1093/jnci/92.14.1172

8. Huang P, Chandra V, Rastinejad F (2010) Structural overview of the nuclear receptor superfamily: insights into physiology and therapeutics. Annu Rev Physiol 72:247-272. https://doi.org/10.1146/ annurev-physiol-021909-135917

9. Africander DJ, Storbeck K-H, Hapgood JP (2014) A comparative study of the androgenic properties of progesterone and the progestins, medroxyprogesterone acetate (MPA) and norethisterone acetate (NET-A). J Steroid Biochem Mol Biol 143:404 415. https:// doi.org/10.1016/j.jsbmb.2014.05.007

10. Louw-du Toit R, Perkins MS, Hapgood JP, Africander D (2017) Comparing the androgenic and estrogenic properties of progestins 
used in contraception and hormone therapy. Biochem Biophys Res Commun 491:140-146. https://doi.org/10.1016/j.bbrc.2017.07.063

11. Smith T, Gillespie M, Eckl V et al (2019) Herbal supplement sales in US increase by $9.4 \%$ in 2018. HerbalGram 123:62-73

12. Dietz BM, Hajirahimkhan A, Dunlap TL, Bolton JL (2016) Botanicals and their bioactive phytochemicals for women's health. Pharmacol Rev 68:1026-1073. https://doi.org/10.1124/pr.115. 010843

13. Dennehy CE (2006) The use of herbs and dietary supplements in gynecology: an evidence-based review. J Midwifery Women's Health 51:402-409. https://doi.org/10.1016/j.jmwh.2006.01.004

14. Patisaul HB, Jefferson W (2010) The pros and cons of phytoestrogens. Front Neuroendocrinol 31:400-419. https://doi. org/10.1016/j.yfrne.2010.03.003

15. Dean M, Murphy BT, Burdette JE (2017) Phytosteroids beyond estrogens: regulators of reproductive and endocrine function in natural products. Mol Cell Endocrinol 442:98-105. https://doi.org/10. 1016/j.mce.2016.12.013

16. Dean M, Austin J, Jinhong R et al (2018) The flavonoid apigenin is a progesterone receptor modulator with in vivo activity in the uterus. Hormones Cancer. https://doi.org/10.1007/s12672-018-0333-x

17. Toh MF, Mendonca E, Eddie SL et al (2014) Kaempferol exhibits progestogenic effects in ovariectomized rats. J Steroids Horm Sci 5: 136. https://doi.org/10.4172/2157-7536.1000136

18. Toh M, Sohn J, Chen S et al (2012) Biological characterization of non-steroidal progestins from botanicals used for women's health. Steroids 77:765-773. https://doi.org/10.1016/j.steroids.2012.03. 013

19. De Bosscher K, Haegeman G (2009) Minireview: latest perspectives on antiinflammatory actions of glucocorticoids. Mol Endocrinol 23:281-291. https://doi.org/10.1210/me.2008-0283

20. Maroon JC, Bost JW, Maroon A (2010) Natural anti-inflammatory agents for pain relief. Surg Neurol Int 1. https://doi.org/10.4103/ 2152-7806.73804

21. Ghasemian M, Owlia S, Owlia MB $(2016,2016)$ Review of antiinflammatory herbal medicines. Adv Pharmacol Sci. https://doi.org/ 10.1155/2016/9130979

22. Pan M-H, Chiou Y-S, Tsai M-L, Ho C-T (2011) Anti-inflammatory activity of traditional Chinese medicinal herbs. J Tradit Complement Med 1:8-24

23. Lee Y, Chung E, Youl Lee K et al (1997) Ginsenoside-Rg1, one of the major active molecules from Panax ginseng, is a functional ligand of glucocorticoid receptor. Mol Cell Endocrinol 133:135140. https://doi.org/10.1016/S0303-7207(97)00160-3

24. De Bosscher K, Berghe WV, Beck IME et al (2005) A fully dissociated compound of plant origin for inflammatory gene repression. Proc Natl Acad Sci U S A 102:15827-15832. https://doi.org/10. 1073/pnas.0505554102

25. Smid-Koopman E, Blok LJ, Kühne LCM et al (2003) Distinct functional differences of human progesterone receptors $\mathrm{A}$ and $\mathrm{B}$ on gene expression and growth regulation in two endometrial carcinoma cell lines. J Soc Gynecol Investig 10:49-57. https://doi.org/ $10.1177 / 107155760301000110$

26. Beato M, Herrlich P, Schütz G (1995) Steroid hormone receptors: many actors in search of a plot. Cell 83:851-857. https://doi.org/10. 1016/0092-8674(95)90201-5

27. Dallakyan S (2010) MGLTools

28. Trott O, Olson AJ (2010) AutoDock Vina: improving the speed and accuracy of docking with a new scoring function, efficient optimization and multithreading. J Comput Chem 31:455-461. https://doi. org/10.1002/jcc. 21334

29. Pettersen EF, Goddard TD, Huang CC et al (2004) UCSF chimeraa visualization system for exploratory research and analysis. $\mathrm{J}$ Comput Chem 25:1605-1612. https://doi.org/10.1002/jcc.20084
30. Colina JA, Varughese P, Karthikeyan S et al Reduced PAX2 expression in murine fallopian tube cells enhances estrogen receptor signaling. Carcinogenesis. https://doi.org/10.1093/carcin/bgz127

31. Morley KL, Ferguson PJ, Koropatnick J (2007) Tangeretin and nobiletin induce G1 cell cycle arrest but not apoptosis in human breast and colon cancer cells. Cancer Lett 251:168-178. https://doi. org/10.1016/j.canlet.2006.11.016

32. Huang KF, Zhang GD, Huang YQ, Diao Y (2012) Wogonin induces apoptosis and down-regulates survivin in human breast cancer MCF-7 cells by modulating PI3K-AKT pathway. Int Immunopharmacol 12:334-341. https://doi.org/10.1016/j.intimp. 2011.12.004

33. Yu JS, Kim AK (2011) Wogonin induces apoptosis by activation of ERK and p38 MAPKs signaling pathways and generation of reactive oxygen species in human breast cancer cells. Mol Cell 31:327335. https://doi.org/10.1007/s10059-011-0041-7

34. Chen P, Lu N, Ling Y et al (2011) Inhibitory effects of wogonin on the invasion of human breast carcinoma cells by downregulating the expression and activity of matrix metalloproteinase-9. Toxicology 282:122-128. https://doi.org/10.1016/j.tox.2011.01. 018

35. Wang N, Ren D, Deng S, Yang X (2014) Differential effects of baicalein and its sulfated derivatives in inhibiting proliferation of human breast cancer MCF-7 cells. Chem Biol Interact 221:99-108. https://doi.org/10.1016/j.cbi.2014.08.003

36. Wang L, Ling Y, Chen Y et al (2010) Flavonoid baicalein suppresses adhesion, migration and invasion of MDA-MB-231 human breast cancer cells. Cancer Lett 297:42-48. https://doi.org/10.1016/ j.canlet.2010.04.022

37. Wang J, Duan Y, Zhi D et al (2014) Pro-apoptotic effects of the novel tangeretin derivate 5-Acetyl-6,7,8,4'-tetramethylnortangeretin on MCF-7 breast cancer cells. Cell Biochem Biophys 70:1255-1263. https://doi.org/10.1007/s12013-014-0049-7

38. Chen Y, Wang J, Hong D-Y et al (2017) Baicalein has protective effects on the $17 \beta$-estradiol-induced transformation of breast epithelial cells. Oncotarget 8:10470-10484. https://doi.org/10.18632/ oncotarget.14433

39. Chen Y, Hong D-Y, Wang J et al (2017) Baicalein, unlike 4hydroxytamoxifen but similar to G15, suppresses $17 \beta$-estradiolinduced cell invasion, and matrix metalloproteinase- 9 expression and activation in MCF-7 human breast cancer cells. Oncol Lett 14: 1823-1830. https://doi.org/10.3892/ol.2017.6298

40. Koubovec D, Ronacher K, Stubsrud E et al (2005) Synthetic progestins used in HRT have different glucocorticoid agonist properties. Mol Cell Endocrinol 242:23-32. https://doi.org/10.1016/j.mce. 2005.07.001

41. Murdoch M, Roberts M (2014) Selective progesterone receptor modulators and their use within gynaecology. Obstet Gynaecol 16:46-50. https://doi.org/10.1111/tog.12072

42. Liang B, Wu L, Xu H et al (2018) Efficacy, safety and recurrence of new progestins and selective progesterone receptor modulator for the treatment of endometriosis: a comparison study in mice. Reprod Biol Endocrinol 16:32. https://doi.org/10.1186/s12958-018-0347-9

43. Chegini N (2010) Proinflammatory and profibrotic mediators: principal effectors of leiomyoma development as a fibrotic disorder. Semin Reprod Med 28:180-203. https://doi.org/10.1055/s-00301251476

44. Augoulea A, Alexandrou A, Creatsa M et al (2012) Pathogenesis of endometriosis: the role of genetics, inflammation and oxidative stress. Arch Gynecol Obstet 286:99-103. https://doi.org/10.1007/ s00404-012-2357-8

45. Enomoto R, Suzuki C, Koshiba C et al (2007) Wogonin prevents immunosuppressive action but not anti-inflammatory effect induced by glucocorticoid. Ann N Y Acad Sci 1095:412-417. https://doi.org/10.1196/annals.1397.044 
46. Madauss KP, Bledsoe RK, Mclay I et al (2008) The first X-ray crystal structure of the glucocorticoid receptor bound to a nonsteroidal agonist. Bioorg Med Chem Lett 18:6097-6099. https:// doi.org/10.1016/j.bmcl.2008.10.021

47. Leung KW, Cheng Y-K, Mak NK et al (2006) Signaling pathway of ginsenoside- $\operatorname{Rg} 1$ leading to nitric oxide production in endothelial cells. FEBS Lett 580:3211-3216. https://doi.org/10.1016/j.febslet. 2006.04.080

48. Du J, Cheng B, Zhu X, Ling C (2011) Ginsenoside Rg1, a novel glucocorticoid receptor agonist of plant origin, maintains glucocorticoid efficacy with reduced side effects. J Immunol 187:942-950. https://doi.org/10.4049/jimmunol.1002579

49. Li X, Wong J, Tsai SY et al (2003) Progesterone and glucocorticoid receptors recruit distinct coactivator complexes and promote distinct patterns of local chromatin modification. Mol Cell Biol 23: 3763-3773. https://doi.org/10.1128/MCB.23.11.3763-3773.2003

50. Ogara MF, Rodríguez-Seguí SA, Marini M et al (2019) The glucocorticoid receptor interferes with progesterone receptor-dependent genomic regulation in breast cancer cells. Nucleic Acids Res 47: 10645-10661. https://doi.org/10.1093/nar/gkz857

51. Wang C-Z, Li X-L, Wang Q-F et al (2010) Selective fraction of Scutellaria baicalensis and its chemopreventive effects on MCF-7 human breast cancer cells. Phytomedicine 17:63-68. https://doi. org/10.1016/j.phymed.2009.07.003

52. Lee W, Ku S-K, Bae J-S (2015) Anti-inflammatory effects of baicalin, baicalein, and wogonin in vitro and in vivo. Inflammation 38:110-125. https://doi.org/10.1007/s10753-0140013-0

53. Qi Z, Yin F, Lu L et al (2013) Baicalein reduces lipopolysaccharideinduced inflammation via suppressing JAK/STATs activation and ROS production. Inflamm Res 62:845-855. https://doi.org/10. 1007/s00011-013-0639-7

54. Yan W, Ma X, Zhao X, Zhang S (2018) Baicalein induces apoptosis and autophagy of breast cancer cells via inhibiting PI3K/AKT pathway in vivo and vitro. Drug Des Devel Ther 12:3961-3972. https:// doi.org/10.2147/DDDT.S181939

55. Yu X, Liu Y, Wang Y et al (2018) Baicalein induces cervical cancer apoptosis through the NF- $\mathrm{kB}$ signaling pathway. Mol Med Rep 17: 5088-5094. https://doi.org/10.3892/mmr.2018.8493
56. Yan H, Xin S, Wang $H$ et al (2015) Baicalein inhibits MMP-2 expression in human ovarian cancer cells by suppressing the $\mathrm{p} 38$ MAPK-dependent NF- $\mathrm{kB}$ signaling pathway. Anti-Cancer Drugs 26:649-656. https://doi.org/10.1097/CAD.0000000000000230

57. Wang Y-F, Xu Y-L, Tang Z-H et al (2017) Baicalein induces Beclin 1 - and extracellular signal-regulated kinase-dependent autophagy in ovarian cancer cells. Am J Chin Med 45:123-136. https://doi.org/ 10.1142/S0192415X17500094

58. Li M, Shi A, Pang H et al (2014) Safety, tolerability, and pharmacokinetics of a single ascending dose of baicalein chewable tablets in healthy subjects. J Ethnopharmacol 156:210-215. https://doi.org/ 10.1016/j.jep.2014.08.031

59. Pang H, Xue W, Shi A et al (2016) Multiple-ascending-dose pharmacokinetics and safety evaluation of baicalein chewable tablets in healthy Chinese volunteers. Clin Drug Investig 36:713-724. https:// doi.org/10.1007/s40261-016-0418-7

60. Zhang L, Li C, Lin G et al (2011) Hepatic metabolism and disposition of baicalein via the coupling of conjugation enzymes and transporters - in vitro and in vivo evidences. AAPS J 13. https:// doi.org/10.1208/s12248-011-9277-6

61. Akao T, Kawabata K, Yanagisawa E et al (2000) Balicalin, the predominant flavone glucuronide of Scutellariae radix, is absorbed from the rat gastrointestinal tract as the aglycone and restored to its original form. J Pharm Pharmacol 52:1563-1568. https://doi.org/ 10.1211/0022357001777621

62. Zhao Q, Chen X-Y, Martin C (2016) Scutellaria baicalensis, the golden herb from the garden of Chinese medicinal plants. Sci Bull (Beijing) 61:1391-1398. https://doi.org/10.1007/s11434-0161136-5

63. McMaster A, Ray DW (2008) Drug insight: selective agonists and antagonists of the glucocorticoid receptor. Nat Clin Pract Endocrinol Metab 4:91-101. https://doi.org/10.1038/ ncpendmet 0745

Publisher's Note Springer Nature remains neutral with regard to jurisdictional claims in published maps and institutional affiliations. 